\title{
Karnofsky Performance Status 80
}

National Cancer Institute

\section{Source}

National Cancer Institute. Karnofsky Performance Status 80. NCI Thesaurus. Code C105710.

Normal activity with effort; some sign or symptoms of disease. 